\title{
Oxalate production via oxidation of ascorbate rather than reduction of carbon dioxide
}

\author{
Fatemeh Khamespanah ${ }^{1,4}$, Maximilian Marx (10 2,4, David B. Crochet ${ }^{1}$, Uttam R. Pokharel ${ }^{1,3}$, Frank R. Fronczek ${ }^{1}$, \\ Andrew W. Maverick (iD ${ }^{1 凶} \&$ Matthias Beller (iD ${ }^{2 凶}$
}

ARISING from Pokharel et al. Nature Communications https://doi.org/10.1038/ncomms6883 (2014)

$\mathrm{n}$ the previous publication, some of us reported the conversion of a copper(I) complex to a copper(II) oxalate complex, and claimed that this conversion involved a reduction of $\mathrm{CO}_{2}$ to oxalate $\left(\mathrm{C}_{2} \mathrm{O}_{4}{ }^{2-}\right)$. Herein, we show that the oxalate is produced not by reduction of $\mathrm{CO}_{2}$, but by reaction of ascorbate with oxygen. We also present new results that explain in a more comprehensive way the behaviour of these copper compounds under $\mathrm{O}_{2}$ and $\mathrm{CO}_{2}$.

Selective reduction of carbon dioxide to $\mathrm{C}_{\geq 2}$ compounds using homogeneous metal complexes is a challenging transformation. Only a limited number of examples have been reported over the past decades ${ }^{1-12}$. In contrast, there has been a vast increase in reported catalysts for selective $\mathrm{CO}_{2}$ reduction to $\mathrm{C}_{1}$ compounds ${ }^{13-15}$. Among the examples reported for the reductive coupling of $\mathrm{CO}_{2}$ to oxalate is a dinuclear $\mathrm{Cu}$ complex introduced by some of us in 2014 (ref. ${ }^{16}$ ). The in situ generated $\mathrm{Cu}(\mathrm{I})$ complex $\left[\mathrm{Cu}_{2}(m-\mathrm{xpt})_{2}\right]\left(\mathrm{PF}_{6}\right)_{2}$ (3) formed by reduction of the $\mathrm{Cu}$ (II) precursor (1) with sodium ascorbate generated an oxalatebridged dinuclear complex (4), proposed to occur via reductive coupling of atmospheric $\mathrm{CO}_{2}$ (Fig. 1). Release of the oxalate by addition of mineral acids was described, potentially enabling stepwise conversion of $\mathrm{CO}_{2}$ into oxalic acid using sodium ascorbate as a comparatively mild reductant.

Interestingly, oxidation of ascorbic acid by transition metal compounds, especially those of copper, has been well-known for more than a century ${ }^{17,18}$. Since then, the reaction mechanisms for such oxidations have been intensely studied ${ }^{18-22}$. More specifically, oxidative degradation of ascorbic acid by (a) inorganic oxidants (sodium periodate ${ }^{23}$, sodium hypoiodite ${ }^{24}$ ); (b) oxygen 25,26 ; and (c) $\mathrm{O}_{2}$ in the presence of $\mathrm{Gd}^{27,28}, \mathrm{Co}^{27}, \mathrm{Pd}^{29}$, $\mathrm{Pt}^{29}, \mathrm{Cd}^{30}, \mathrm{Fe}^{31}$, or $\mathrm{Cu}^{32}$ compounds is reported to yield oxalate as a degradation product (see Supplementary Fig. 21 for a typical reaction sequence).

We now report that the true origin of the oxalate in the communication published in 2014 is not $\mathrm{CO}_{2}$, as it was described, but oxidative degradation of sodium ascorbate.
A first hint towards the oxidative degradation pathway as the origin of oxalate was obtained when treatment of the in situ generated $\mathrm{Cu}(\mathrm{I})$ complex $\left[\mathrm{Cu}_{2}(m-\mathrm{xpt})_{2}\right]\left(\mathrm{PF}_{6}\right)_{2}$ (3), formed via reaction of the $\mathrm{Cu}$ (II) precursor 1 with sodium ascorbate in DMF, with $\mathrm{CO}_{2}$ over 6 days did not result in the previously described colour change from yellow to green (Supplementary Fig. 1) and no $\mathrm{Cu}(\mathrm{II})$ species was detected by UV/Vis spectroscopy (Supplementary Fig. 2). However, after introduction of air, oxidation of the $\mathrm{Cu}(\mathrm{I})$ complex 3 was observed and followed by UV/Vis spectroscopy over $189 \mathrm{~h}$, resembling the UV/Vis spectra reported in the previous publication.

The product obtained from this reaction after slow evaporation of the solvent was identical to the reported oxalate complex 4 , as evident from the IR spectrum (Supplementary Fig. 3).

Since the reaction seemed to require air for the formation of oxalate, we suggested that oxidation of the ascorbate might be the true origin of the oxalate. Therefore, the previously published results might have eventuated from oxygen contamination of the reaction mixtures utilised for the labelling studies and the UV/Vis spectroscopic study.

To test this hypothesis, we prepared the $\mathrm{Cu}(\mathrm{I})$ complex 3 in situ using sodium ascorbate, and exposed it to oxygen in the absence of air and $\mathrm{CO}_{2}$. Indeed, oxidation of the $\mathrm{Cu}(\mathrm{I})$ complex 3 in the presence of $\mathrm{O}_{2}$ occurred within a few minutes, as evidenced by a characteristic colour change from yellow to green (Supplementary Fig. 5) and after 5 days of reaction time, a yellow to green solid was obtained after removal of the solvent. As suspected, the solid product was identical to that obtained via the reaction of the in situ generated $\mathrm{Cu}(\mathrm{I})$ complex 3 with air, as evident from X-ray analysis and FTIR spectroscopy (see spectra in Fig. 2).

Complex 4 was even obtained from a mixture of $\mathrm{Cu}(\mathrm{II})$ complex 1 and DHA in air, demonstrating that $\mathrm{Cu}(\mathrm{I})$ is not required for oxalate formation.

The $\mathrm{Cu}(\mathrm{I})$ complex $\left[\mathrm{Cu}_{2}(m-\mathrm{xpt})_{2}\right]^{2+}$ can also be prepared without ascorbate or dehydroascorbic acid, for example, by

\footnotetext{
${ }^{1}$ Department of Chemistry, Louisiana State University, Baton Rouge, LA, USA. ${ }^{2}$ Leibniz Institute for Catalysis at the University of Rostock, Rostock, Germany. ${ }^{3}$ Present address: Department of Chemistry and Physical Sciences, Nicholls State University, Thibodaux, LA, USA. ${ }^{4}$ These authors contributed equally: Fatemeh Khamespanah, Maximilian Marx.凶email: maverick@lsu.edu; Matthias.Beller@catalysis.de
} 


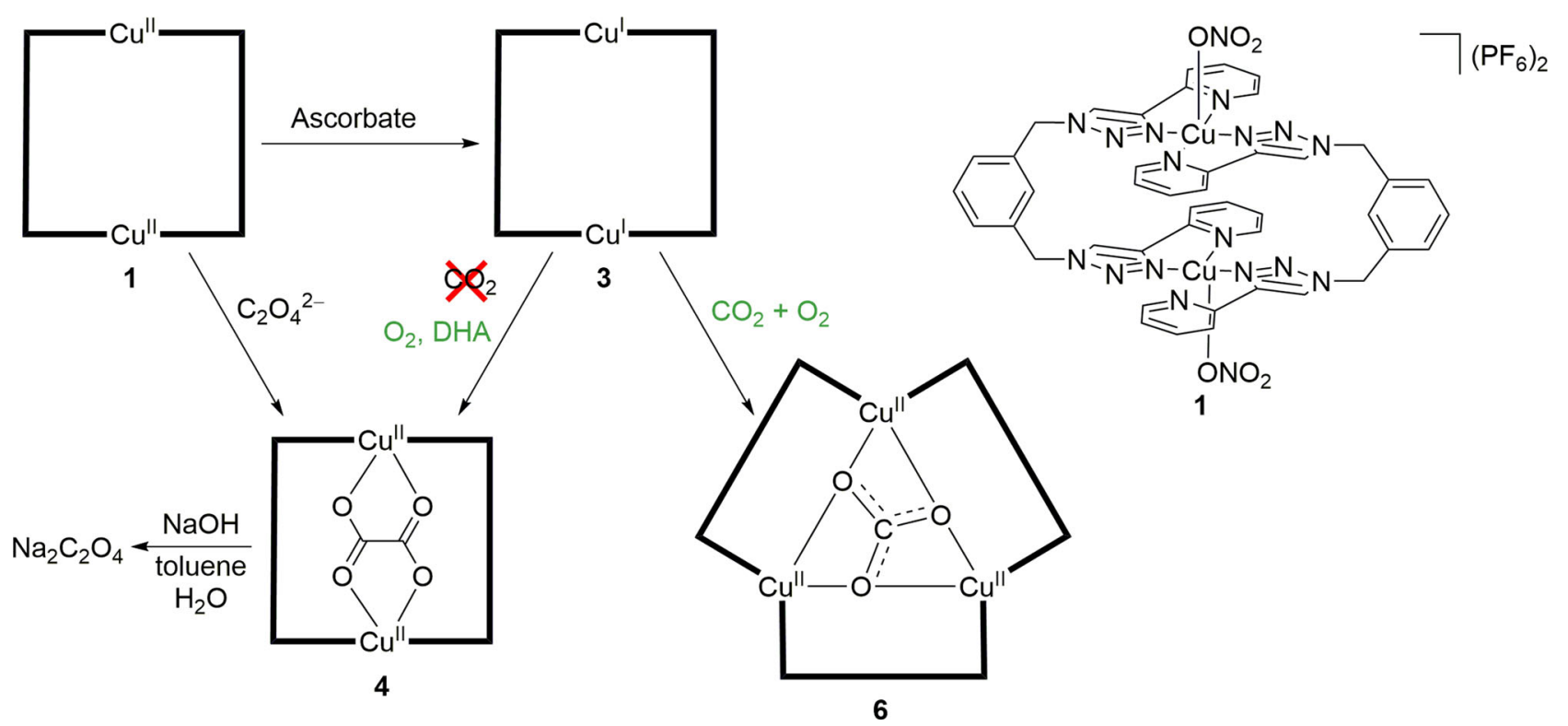

Fig. 1 Reactions of $\mathrm{Cu}(\mathrm{II})$ complex $\mathbf{1}$ and the $\mathbf{C u}(\mathrm{I})$ complex $\mathbf{3}$ obtained by reduction of $\mathbf{1}$ with ascorbate. For the formation of oxalate complex $\mathbf{4}$ from 3, $\mathrm{CO}_{2}$ was previously reported to be required. We show here that the reaction requires ascorbate or dehydroascorbic acid (DHA), and oxygen. If ascorbate and DHA are absent, oxidation of $\mathbf{3}$ in air produces $\mathbf{6}$. All reactions were conducted in DMF, except for the removal of oxalate from $\mathbf{4}$ (Note: 1, $\mathbf{3}$, and $\mathbf{4}$ represent the same compounds as in ref. ${ }^{16}$ ).

(a) $\mathrm{Na}$ ascorbate,
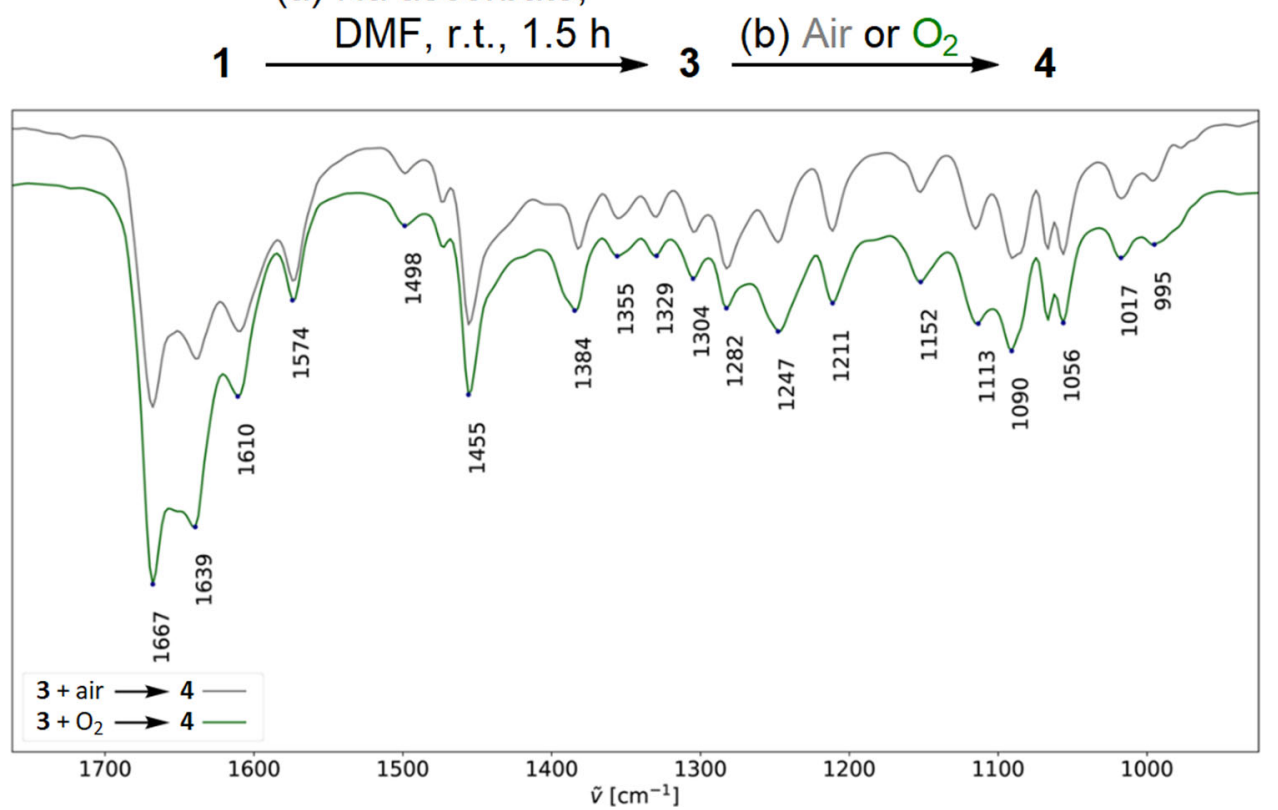

Fig. 2 Formation of the oxalate complex $\mathbf{4}$ from $\mathbf{3}$ requires $\mathbf{O}_{\mathbf{2}}$ and does not require $\mathbf{C O}_{2}$. FTIR spectra for the products obtained when $\mathbf{3}$ (prepared in situ from 1 and ascorbate) was exposed to air (grey) or pure $\mathrm{O}_{2}$ (green) are identical (details are given in the ESI).

reaction of $\mathrm{Cu}\left(\mathrm{BF}_{4}\right)_{2}$ with $\mathrm{Cu}$ foil in DMF in the presence of $m$ xpt. This yellow solution of $\left[\mathrm{Cu}_{2}(m-\mathrm{xpt})_{2}\right]\left(\mathrm{BF}_{4}\right)_{2}(\mathbf{3 a}$, identical to 3 except for the counterion) (a) does not react with $\mathrm{CO}_{2}$; (b) reacts with air to produce the new trinuclear $\mathrm{Cu}(\mathrm{II})$ carbonate complex $\left[\mathrm{Cu}_{3}(m \text {-xpt })_{3}\left(\mu_{3}-\mathrm{CO}_{3}\right)\right]\left(\mathrm{BF}_{4}\right)_{4}(\mathbf{6})$; and (c) can be converted to the oxalate complex $\left[\mathrm{Cu}_{2}(m \text {-xpt })_{2}\left(\mu-\mathrm{C}_{2} \mathrm{O}_{4}\right)\right]\left(\mathrm{BF}_{4}\right)_{2}(\mathbf{4 b})$ by reaction with air or $\mathrm{O}_{2}$, but only if DHA is added. These observations are also in accordance with ascorbate being the source of oxalate. The structures of $\mathbf{6}$ and $\mathbf{4 b}$ were determined by X-ray analysis (see Supplementary Fig. 13).

In the previous publication, an isotope labelling experiment was conducted by treating in situ generated 3 with ${ }^{13} \mathrm{CO}_{2}$. In mass spectrometry experiments performed on $\mathbf{4}$ at that time, we did not observe signals attributable to oxalate-containing product ions; however, its FTIR spectrum appeared to show a shift of $\Delta \tilde{v}_{\mathrm{CO}}=$ $-19 \mathrm{~cm}^{-1}$. Since this shift was only half the expected magnitude, we re-performed the labelling studies. In the new experiments, treatment of in situ generated $\mathbf{3}$ with ${ }^{13} \mathrm{CO}_{2}-\mathrm{O}_{2}$ (1:1) produced only unlabelled 4, whose ESI-MS shows a monoisotopic ion at $1147.1321 \mathrm{amu}$ for $\left[\mathrm{Cu}_{2}(m-\mathrm{xpt})_{2}\left(\mu-\mathrm{C}_{2} \mathrm{O}_{4}\right)\right]\left(\mathrm{PF}_{6}\right)^{+}$(see Supplementary Fig. 9). The ${ }^{13} \mathrm{C}$-labelled oxalate complex $\mathbf{4}^{-13} \mathrm{C}_{2}$ was obtained, for reference, by reaction of the starting complex 1 with $\left(\mathrm{Bu}_{4} \mathrm{~N}\right)_{2}\left({ }^{13} \mathrm{C}_{2} \mathrm{O}_{4}\right)$; monoisotopic ion $1149.1373 \mathrm{amu}$. This analysis clearly demonstrates that oxalate does not arise from $\mathrm{CO}_{2}$ 
reduction. FTIR spectra of the new products show $\Delta \tilde{v}_{\mathrm{CO}}=-39 \mathrm{~cm}$ -1 , close to the expected value (see Supplementary Fig. 8). A similar value for $\Delta \tilde{v}_{\mathrm{CO}}$ is also estimated based on DFT calculations; detailed results are given in the ESI.

In the previous publication, the IR absorption at ca. $1670 \mathrm{~cm}^{-1}$ in 4 was assigned to the oxalate $\mathrm{C}-\mathrm{O}$ stretching vibration. However, as demonstrated in Supplementary Fig. 14, this absorption is caused by co-crystallized DMF in $\mathbf{4}\left(\tilde{v}_{\mathrm{CO}}\right.$ for the bound oxalate is $1639 \mathrm{~cm}^{-1}$ ). In the previous experiment with ${ }^{13} \mathrm{CO}_{2}, 4$ appeared to show an absorption at $1650 \mathrm{~cm}^{-1}$; we now know that this sample did not contain ${ }^{13} \mathrm{C}_{2} \mathrm{O}_{4}{ }^{2-}$. The spectra in Supplementary Fig. 7 suggest that different samples of 4 may show varying absorption in the $1670-1640 \mathrm{~cm}^{-1}$ region. This variability may have led to the incorrect assignment of an apparent ${ }^{13} \mathrm{C}$ shift in the previous work.

Due to this complexity of the IR spectra, we searched for additional experimental evidence for the formation of oxalate from the reaction under $\mathrm{O}_{2}$ atmosphere. We repeated the previously described oxalate removal by treatment with aqueous $\mathrm{HNO}_{3}$ (ref. ${ }^{16}$ ), but we could not detect the expected $\mathrm{H}_{2} \mathrm{C}_{2} \mathrm{O}_{4}$ by ${ }^{13} \mathrm{C}$ NMR spectroscopy. Therefore, we adapted a procedure which was utilised for the isolation of $\mathrm{Na}_{2} \mathrm{C}_{2} \mathrm{O}_{4}$ from similar $\mathrm{Cu}$ oxalate complexes ${ }^{33}$. We used this procedure to isolate $\mathrm{Na}_{2} \mathrm{C}_{2} \mathrm{O}_{4}$ (verified by ${ }^{13} \mathrm{C}$ NMR spectroscopy), from samples of $\mathbf{4}$ obtained by reaction of in situ generated 3 with (a) air (i.e. $\mathrm{O}_{2}+\mathrm{CO}_{2}$; Supplementary Fig. 18), and (b) pure $\mathrm{O}_{2}$ (i.e. without $\mathrm{CO}_{2}$; Supplementary Fig. 16). In the latter case, the isolation of $\mathrm{Na}_{2} \mathrm{C}_{2} \mathrm{O}_{4}$ from 4 was conducted under argon, so the isolated oxalate could not be formed by any reaction requiring $\mathrm{CO}_{2}$.

In summary, we have demonstrated that the $\mathrm{Cu}$ complex reported in the previous communication does not form oxalate via $\mathrm{CO}_{2}$ reduction. Instead, oxalate forms by oxidative degradation of ascorbate. This was finally evidenced by the reaction conducted under an atmosphere of $\mathrm{O}_{2}$, giving rise to the same oxalate complex described earlier (ref. ${ }^{16}$ ) from which sodium oxalate was removed and identified by NMR spectroscopy. In addition, the same product was obtained from reactions of the $\mathrm{Cu}$ (I) complex $\left[\mathrm{Cu}_{2}(m-\mathrm{xpt})_{2}\right]^{2+}$ with $\mathrm{O}_{2}$ or air in the presence of DHA. In experiments with $\left[\mathrm{Cu}_{2}(m \text {-xpt })_{2}\right]^{2+}$ under ${ }^{13} \mathrm{CO}_{2}+\mathrm{O}_{2}$, ${ }^{13} \mathrm{C}$ was not incorporated into the oxalate product. In contrast, a new trinuclear $\mathrm{Cu}(\mathrm{II})$ carbonate complex, $\left[\mathrm{Cu}_{3}(m-\right.$ $\left.\mathrm{xpt})_{3}\left(\mu-\mathrm{CO}_{3}\right)\right]^{4+}$, has been isolated, when $\left[\mathrm{Cu}_{2}(m-\mathrm{xpt})_{2}\right]^{2+}$ was treated with $\mathrm{CO}_{2}$ and $\mathrm{O}_{2}$ in the absence of sodium ascorbate or DHA. Since reproducibility is not always given for challenging transformations, such as the reductive coupling of $\mathrm{CO}_{2}{ }^{34}$, this report clearly highlights the importance of further mechanistic investigations on previously published systems.

\section{Data availability}

Accession codes: The X-ray crystallographic data for structures reported in this article have been deposited at the Cambridge Crystallographic Data Centre (CCDC), under deposition numbers CCDC 1976241 (4b) and 1976240 (6). These data can be obtained free of charge from the Cambridge Crystallographic Data Centre via https://www.ccdc. cam.ac.uk/structures/. Other data are available from the authors.

Received: 22 January 2020; Accepted: 2 February 2021; Published online: 25 March 2021

\section{References}

1. Cook, B. J., Di Francesco, G. N., Abboud, K. A. \& Murray, L. J. Countercations and solvent influence $\mathrm{CO}_{2}$ reduction to oxalate by chalcogen-bridged tricopper cyclophanates. J. Am. Chem. Soc. 140, 5696-5700 (2018).

2. Angamuthu, R., Byers, P., Lutz, M., Spek, A. L. \& Bouwman, E. Electrocatalytic $\mathrm{CO}_{2}$ conversion to oxalate by a copper complex. Science 327, 313-315 (2010).
3. Farrugia, L. J., Lopinski, S., Lovatt, P. A. \& Peacock, R. D. Fixing carbon dioxide with copper: crystal structure of $\left[\mathrm{LCu}\left(\mu-\mathrm{C}_{2} \mathrm{O}_{4}\right) \mathrm{CuL}\right]\left[\mathrm{Ph}_{4} \mathrm{~B}\right]_{2}(\mathrm{~L}=\mathrm{N}$, $\mathrm{N}^{\prime}, \mathrm{N}^{\prime \prime}$-Triallyl-1,4,7-triazacyclononane). Inorg. Chem. 40, 558-559 (2001).

4. Saouma, C. T., Lu, C. C., Day, M. W. \& Peters, J. C. $\mathrm{CO}_{2}$ reduction by $\mathrm{Fe}(\mathrm{I})$ : solvent control of C-O cleavage versus $\mathrm{C}-\mathrm{C}$ coupling. Chem. Sci. 4, 4042-4051 (2013).

5. Klose, A. et al. The metal-carbon multiple bond in iron(I)- and iron (II)-dibenzotetramethyltetra[14] azaannulene: carbene, carbonyl, and isocyanide derivatives. J. Organomet. Chem. 591, 45-62 (1999).

6. Tanaka, K. Reduction of $\mathrm{CO}_{2}$ directed toward carbon-carbon bond formation. Bull. Chem. Soc. Jpn. 71, 17-29 (1998).

7. Horn, B., Limberg, C., Herwig, C. \& Braun, B. Nickel(I)-mediated transformations of carbon dioxide in closed synthetic cycles: reductive cleavage and coupling of $\mathrm{CO}_{2}$ generating $\mathrm{Ni}^{\mathrm{I}} \mathrm{CO}, \mathrm{Ni}^{\mathrm{II}} \mathrm{CO}_{3}$ and $\mathrm{Ni}^{\mathrm{II}} \mathrm{C}_{2} \mathrm{O}_{4} \mathrm{Ni}^{\mathrm{II}}$ entities. Chem. Commun. 49, 10923-10925 (2013).

8. Rudolph, M., Dautz, S. \& Jäger, E.-G. Macrocyclic $\left[\mathrm{N}_{4}{ }^{2-}\right]$ coordinated nickel complexes as catalysts for the formation of oxalate by electrochemical reduction of carbon dioxide. J. Am. Chem. Soc. 122, 10821-10830 (2000).

9. Fröhlich, H.-O. \& Schreer, H. Einschub und reduktive Kopplung von $\mathrm{CO}_{2}$; zur Bildung von $\mathrm{Cp}_{2} \mathrm{Ti}^{\mathrm{III}} \mathrm{C}_{2} \mathrm{O}_{4} \mathrm{Ti}^{\mathrm{III}} \mathrm{Cp}_{2}$ und $\mathrm{Cp}_{2} \mathrm{Ti}^{\mathrm{IV}}\left(-\mathrm{O}_{2} \mathrm{C}\left(\mathrm{CH}_{2}\right)_{3} \mathrm{NRCH}_{2} \mathrm{CH}_{2} \mathrm{NR}\right.$ $\left.\left(\mathrm{CH}_{2}\right)_{3} \mathrm{CO}_{2}{ }^{-}\right)\left(\mathrm{R}=i-\mathrm{C}_{4} \mathrm{H}_{9}\right)$. Z. Chem. 23, 348-349 (1983).

10. Evans, W. J., Lorenz, S. E. \& Ziller, J. W. Investigating metal size effects in the $\operatorname{Ln}_{2}\left(\mu-\eta^{2}: \eta^{2}-\mathrm{N}_{2}\right)$ reduction system: reductive reactivity with complexes of the largest and smallest trivalent lanthanide ions, $\mathrm{La}^{3+}$ and $\mathrm{Lu}^{3+}$. Inorg. Chem. 48, 2001-2009 (2009).

11. Evans, W. J., Seibel, C. A. \& Ziller, J. W. Organosamarium-mediated transformations of $\mathrm{CO}_{2}$ and COS: monoinsertion and disproportionation reactions and the reductive coupling of $\mathrm{CO}_{2}$ to $\left[\mathrm{O}_{2} \mathrm{CCO}_{2}\right]^{2-}$. Inorg. Chem. 37, 770-776 (1998).

12. Arnold, P. L. \& Turner, Z. R. Carbon oxygenate transformations by actinide compounds and catalysts. Nat. Rev. Chem. 1, 0002 (2017).

13. Francke, R., Schille, B. \& Roemelt, M. Homogeneously catalyzed electroreduction of carbon dioxide-methods, mechanisms, and catalysts. Chem. Rev. 118, 4631-4701 (2018).

14. Windle, C. D. \& Perutz, R. N. Advances in molecular photocatalytic and electrocatalytic $\mathrm{CO}_{2}$ reduction. Coord. Chem. Rev. 256, 2562-2570 (2012).

15. Wang, W.-H., Himeda, Y., Muckerman, J. T., Manbeck, G. F. \& Fujita, E. $\mathrm{CO}_{2}$ hydrogenation to formate and methanol as an alternative to photo- and electrochemical $\mathrm{CO}_{2}$ reduction. Chem. Rev. 115, 12936-12973 (2015).

16. Pokharel, U. R., Fronczek, F. R. \& Maverick, A. W. Reduction of carbon dioxide to oxalate by a binuclear copper complex. Nat. Commun. 5, 5883 (2014).

17. Creutz, C. Complexities of ascorbate as a reducing agent. Inorg. Chem. 20, 4449-4452 (1981).

18. Davies, M. B. Reactions of L-ascorbic acid with transition metal complexes. Polyhedron 11, 285-321 (1992).

19. Yano, Y., Takano, S., Kato, Y. \& Tagaki, W. Oxidation of ascorbic acid by a trivalent copper complex. J. Chem. Soc. Perkin Trans. 2, 1227-1229 (1979).

20. Xu, J. \& Jordan, R. B. Kinetics and mechanism of the reaction of aqueous copper(II) with ascorbic acid. Inorg. Chem. 29, 2933-2936 (1990).

21. Scarpa, M., Vianello, F., Signor, L., Zennaro, L. \& Rigo, A. Ascorbate oxidation catalyzed by bis(histidine)copper(II). Inorg. Chem. 35, 5201-5206 (1996).

22. Nayak, S. \& Dash, A. C. Mechanistic study of the reactions of L-ascorbic acid and oxalic acid with an octahedral manganese(IV) complex of 1,8-bis(2hydroxybenzamido)-3,6-diazaoctane. Transit. Met. Chem. 31, 316-324 (2006).

23. Harkrader, R. J., Plunkett, L. M. \& Tolbert, B. M. Periodate degradation of labeled ascorbic acid. Anal. Biochem. 72, 310-314 (1976).

24. Herbert, R. W., Hirst, E. L., Percival, E. G. V., Reynolds, R. J. W. \& Smith, F. The constitution of ascorbic acid. J. Chem. Soc. 1270-1290 (1933).

25. Shin, D. B. \& Feather, M. S. The degradation of L-ascorbic acid in neutral solutions containing oxygen. J. Carbohydr. Chem. 9, 461-469 (1990).

26. Kurata, T., Miyake, N. \& Otsuka, Y. Formation of L-threonolactone and oxalic acid in the autoxidation reaction of L-ascorbic acid. Biosci. Biotechnol. Biochem. 60, 1212-1214 (1996).

27. Ünaleroğlu, C., Zümreoğlu-Karan, B., Zencir, Y. \& Hökelek, T. pHindependent decomposition reactions of L-ascorbic acid in aqueous metal solutions-I. Formation and structures of $\mathrm{Co}^{\mathrm{II}}$ and $\mathrm{Gd}^{\mathrm{III}}$ oxalates. Polyhedron 16, 2155-2161 (1997).

28. Magda, D. et al. Motexafin gadolinium reacts with ascorbate to produce reactive oxygen species. Chem. Commun. 2730-2731 (2002).

29. Arendse, M. J., Anderson, G. K. \& Rath, N. P. Oxidative degradation of the ascorbate anion in the presence of platinum and palladium. Formation and structures of platinum and palladium oxalate complexes. Polyhedron 20, 2495-2503 (2001).

30. Orioli, P., Bruni, B., Di Vaira, M., Messori, L. \& Piccioli, F. Decomposition of ascorbic acid in the presence of cadmium ions leads to formation of a polymeric cadmium oxalate species with peculiar structural features. Inorg. Chem. 41, 4312-4314 (2002). 
31. de Ruiter, G. et al. The system iron(II)/mpzbpy mediates the $\mathrm{H}_{2} \mathrm{O}_{2}$ oxidation of cyclohexane and cyclooctene and the aerobic oxidative cleavage of ascorbic acid to oxalate. Inorg. Chem. Commun. 11, 787-790 (2008).

32. Thomas, A. M., Mandal, G. C., Tiwary, S. K., Rath, R. K. \& Chakravarty, A. R. Ascorbate oxidation leading to the formation of a catalytically active oxalato bridged dicopper(II) complex as a model for dopamine $\beta$-hydroxylase. J. Chem. Soc. Dalton Trans. 1395-1396 (2000).

33. Takisawa, H., Morishima, Y., Soma, S., Szilagyi, R. K. \& Fujisawa, K. Conversion of carbon dioxide to oxalate by a-ketocarboxylatocopper(II) complexes. Inorg. Chem. 53, 8191-8193 (2014).

34. Thomas, A. M., Lin, B.-L., Wasinger, E. C. \& Stack, T. D. P. Ligand noninnocence of thiolate/disulfide in dinuclear copper complexes: solventdependent redox isomerization and proton-coupled electron transfer. J. Am. Chem. Soc. 135, 18912-18919 (2013).

\section{Acknowledgements}

M.M. is grateful to the Fonds der Chemischen Industrie for a Kekulé scholarship. Research at Louisiana State University was supported by the West Professorship.

\section{Author contributions}

F.K., M.M., D.B.C., and U.R.P. performed the synthetic work, and conducted the spectroscopic analyses. F.R.F. performed X-ray analysis. F.K., M.M., M.B., and A.W.M. contributed to writing.

\section{Competing interests}

The authors declare no competing interests.

\section{Additional information}

Supplementary information The online version contains supplementary material available at https://doi.org/10.1038/s41467-021-21817-w.

Correspondence and requests for materials should be addressed to A.W.M. or M.B.

Peer review information Nature Communications thanks the anonymous reviewers for their contribution to the peer review of this work.

Reprints and permission information is available at http://www.nature.com/reprints

Publisher's note Springer Nature remains neutral with regard to jurisdictional claims in published maps and institutional affiliations.

(c) (i) Open Access This article is licensed under a Creative Commons Attribution 4.0 International License, which permits use, sharing, adaptation, distribution and reproduction in any medium or format, as long as you give appropriate credit to the original author(s) and the source, provide a link to the Creative Commons license, and indicate if changes were made. The images or other third party material in this article are included in the article's Creative Commons license, unless indicated otherwise in a credit line to the material. If material is not included in the article's Creative Commons license and your intended use is not permitted by statutory regulation or exceeds the permitted use, you will need to obtain permission directly from the copyright holder. To view a copy of this license, visit http://creativecommons.org/ licenses/by/4.0/.

(C) The Author(s) 2021 